\title{
RANCANG BANGUN BEL OTOMATIS DI STIKOM TUNAS BANGSA BERBASIS ARDUINO DILENGKAPI DENGAN OUTPUT SUARA
}

\author{
Fachrul Hasby $^{1}$, Sumarno ${ }^{2}$, Zulaini Masruro Nasution ${ }^{3}$ \\ ${ }^{1}$ Program Studi Teknik Informatika, STIKOM Tunas Bangsa Pematangsiantar \\ ${ }^{1}$ fahrulhasby11@gmail.com, \\ ${ }^{1}$ Program Studi Teknik Informatika, STIKOM Tunas Bangsa Pematangsiantar \\ ${ }^{2}$ sumarno@amiktunasbangsa.ac.id, \\ ${ }^{1}$ Program Studi Teknik Informatika, STIKOM Tunas Bangsa Pematangsiantar \\ ${ }^{3}$ zulaini@amiktunasbangsa.ac.id
}

\begin{tabular}{ll}
\hline ARTICLE INFO & ABSTRACT \\
\hline
\end{tabular}

Article history:

Received : 28 - Agustus - 2021

Received in revised form : 7 - September - 2021

Accepted : 11 - Oktober - 2021

Available online : 16 - Oktober - 2021
Bell is certainly no stranger to education. In general, the bell still uses human power to ring it. It is still rare in the world of education to use an automatic bell that can work alone according to a predetermined time in the teaching and learning process. The purpose of the design of automatic bells at STIKOM Tunas Bangsa Pematangsiantar is to facilitate the work of picket officers and optimize the time for teaching and learning. The work process of this tool is to input the predetermined lesson time into the Arduino Uno Microcontroller using $\mathbf{C}$ language in the Arduino IDE Software. After that the microcontroller will read the program schedule hours that have been inputted into the microcontroller. If the program inputted matches the time schedule of today's lesson hours, the bell will automatically output the output in the form of an information notification sound. This tool also has a 16x2 Keypad Shield for setting the manual in the test mode that is matched in the time of the ongoing test and automatically produces notification sound output, where the automatic bell is fully controlled with the Arduino Uno Microcontroller command and the time setting that has been set into the RTC ( Real Time Clock) as a time saver.

Keywords: Arduino Uno, RTC, Keypad Shield 16x2, STIKOM Tunas Bangsa

\footnotetext{
Abstrak

Bel tentunya sudah tidak asing lagi dalam dunia pendidikan. Pada umumnya bel masih menggunakan tenaga manusia untuk membunyikannya. Masih jarang dalam dunia pendidikan menggunakan bel otomatis yang dapat bekerja sendiri sesuai waktu yang telah ditentukan dalam proses belajar mengajar. Tujuan dari perancangan bel otomatis di STIKOM Tunas Bangsa Pematangsiantar adalah mempermudah pekerjaan petugas piket serta pengoptimalkan waktu yang tepat untuk proses belajar mengajar. Proses kerja alat ini adalah dengan meng input waktu jam pelajaran yang sudah ditentukan ke
} 
dalam Microcontroller Arduino Uno menggunakan bahasa C di Software Arduino IDE. Setelah itu Microcontroller akan akan membaca program jadwal jam pelajaran yang telah di input ke dalam Microcontroller. Apabila program yang di input cocok dengan jadwal waktu jam pelajaran hari ini maka secara otomatis bel akan mengeluarkan hasil output dalam bentuk suara pemberitahuan informasi. Alat ini juga memiliki Keypad Shield 16x2 untuk mensetting manual dalam mode ujian yang dicocokan dalam waktu ujian yang sedang berlangsung dan secara otomatis menghasilkan output suara pemberitahuan, dimana bel otomatis ini sepenuhnya dikendalikan dengan perintah Microcontroller Arduino Uno dan penempatan waktu yang telah disetting ke dalam RTC (Real Time Clock) sebagai penyimpan waktu.

\section{Kata Kunci : Arduino Uno, RTC, Keypad Shield 16x2, STIKOM Tunas Bangsa}

\section{Pendahuluan}

Pendidikan merupakan asas untuk kemajuan bangsa dalam menciptakan karakter setiap manusia yang mempunyai inovasi dan ide untuk membentuk pembangunan suatu Negara. Di Negara Indonesia ini merupakan salah satu yang mengutamakan pendidikan untuk visi misi mencerdaskan generasi muda bangsa dan untuk kemajuan negara yang dapat dilihat dari palaksanaan mengalokasikan APBN pendidikan yang semakin besar. Membahas tentang pendidikan tentunya tidak lepas dari peran sebagai sarana implementasi proses pembelajaran belajar mengajar. Kedisiplinan waktu dalam proses belajar mengajar selalu dikaitkan dengan pergantian waktu belajar. Dan pemberitahuan proses belajar mengajar dikaitkan dengan bel. Bel adalah alat yang efisien dapat mengeluarkan bunyi dan memiliki fungsi untuk memberikan informasi sebagai kode atau pun pengingat khususnya dalam proses belajar mengajar. STIKOM Tunas Bangsa Pematangsiantar Perlu diketahui bahwasannya di perguruan tinggi STIKOM Tunas Bangsa Pematangsiantar untuk bel pergantian jam ataupun pemberitahuan waktu istirahat masih manual dan setiap harinya menggunakan jasa piket yang akan menekannya untuk membunyikan bel bahwasannya pergantian matakuliah ataupun jam waktu istirahat. Tanda pemberitahuan informasi yang dilakukan secara manual ini memiliki tingkat yang rendah dari segi keakuratannya. Keterlambatan dalam membunyikan bel pergantian jam pelajaran atau pun waktu istirahat sering mengakibatkan terhambatnya sistem proses belajar dan mengajar pada jam pelajaran selanjutnya. Dalam melancarkan penelitian ini, penulis memanfaatkan beberapa referensi pada penelitian sebelumnya. Hal ini dilakukan untuk mempertimbangkan tingkat daya guna dan kreativitas dalam pembuatan bel otomatis berbasis microcontroller Arduino Uno. Kinerja bel otomatis saat pertama dihidupkan arduino akan melakukan pemberian nilai variabel dan menentukan port pada Arduino yang akan digunakan sesuai dengan program yang telah di upload, kemudian melakukan proses pembacaan nilai RTC dan menampilkannya di LCD (8). Kemudian arduino akan membaca isi memori eepromnya. Jika nilai pada eeprom, pada variabel hari, jam, menit dan detik telah sesuai dengan yang ada pada RTC sebagaimana yang ditampilkan di LCD maka Arduino akan memproses nilai tersebut untuk selanjutnya mengendalikan audio player sehingga kemudian audio player memainkan file audio sesuai dengan yang sudah diatur pada jam dimulainya pelajaran, istirahat, maupun ketika jam berakhir.

Bell adalah sebuah alat penanda yang banyak digunakan oleh masyarakat baik pribadi maupun intitusi pendidikan, biasanya bell digunakan untuk penanda adanya Tamu sehingga Tuan rumah akan tahu jika didepan rumah ada seseorang yang mempunyai kepentingan, hal ini sangat membantu baik dipihak tamu maupun tuan rumah. Begitu juga di dalam institute di pendidikan, tidak hanya pendidikan formal, pendidikan informalpun sangat membutuhkan adanya bel, didalam pendidikan formal bel digunakan untuk penanda mengawali atau mengakhiri suatu pembelajaran dan di dalam pendidikan informal seperti pondok pesantren (11). Mikrokontroler adalah sebuah sistem komputer yang seluruh atau sebagian besar elemennya dikemas dalam satu keeping IC (Integreted Circuits) sehingga sering disebut mikrokomputer cip tunggal.. Di dalamnya terkandung sebuah inti prosesor, memori (sejumlah kecil RAM, memori program, atau keduanya), dan perlengkapan input output. Dengan kata lain, mikrokontroler adalah suatu alat elektronika digital yang mempunyai masukan dan keluaran serta kendali dengan program yang bisa ditulis dan dihapus dengan cara khusus, cara kerja mikrokontroler sebenarnya membaca dan menulis data. Arduino adalah kit elektronik atau papan rangkaian elektronik open source yang di dalamnya terdapat komponen utama, yaitu sebuah chip mikrokontroler dengan jenis AVR dari perusahaan Atmel" (7). Arduino adalah pengendali mikro single-board yang bersifat open-source, diturunkan dari Wiring platform, dirancang untuk memudahkan penggunaan elektronik dalam berbagai bidang (10). Real Time Clock atau sering disebut juga RTC merupakan salah satu komponen elektronika aktif yang dapat menyimpan data tanggal dan waktu di dalamnya. Data waktu ini sering kali digunakan untuk membuat sebuah alat penjadwalan terpadu atau hanya sekedar jam digital. Modul RTC DS3231 merupakan serial modul waktu DILENGKAPI DENGAN OUTPUT SUARA - Fachrul Hasby ${ }^{1}$ 
yang menyediakan informasi detik, menit, jam, hari, bulan dan tahun. Dapat beroperasi dengan format waktu 24 jam maupun $12 \mathrm{jam}$ am/pm. DS3231 juga memiliki rangkaian deteksi tegangan drop dan secara otomatis akan berganti ke baterai cadangan (9). LCD ( Liquid Crystal Display ) Sementara blok LCD 16x2 merupakan sebuah perangkat LCD yang digunakan untuk menampilkan informasi tanggal dan waktu dari mesin bell (6). Mesin bel dapat memainkan file suara atau audio dalam format .mp3 dan .wav melalui komponen DFP layer ini. Pada komponen DFP layer ini terdapat sebuah mini SD Card yang akan diisi file-file suara atau audio bel sekolah seperti suara untuk menyampaikan jam masuk kelas, pergantian jam pelajaran, upacara dan file-file pendukung lainnya. Adaptor Power Supply atau dalam Bahasa Indonesia disebut dengan catu daya adalah suatu alat listrik yang dapat menyediakan energi listrik untuk perangkat listrik ataupun elektronika lainnya. Pada dasarnya power supply atau catu daya ini memerlukan sumber energi listrik yang kemudian mengubahnya menjadi energi listrik yang dibutuhkan oleh perangkat elektronika lainnya. Oleh karenaa itu power supply kadang - kadang disebut juga dengan istilah Electric Power Converter (3).Untuk proses penelitian ini menggunakan Breadboard yaitu Sejumlah lubang pada breadboard sebenarnya dalam keadaan terhubung. Oleh karena itu, memahami hubungan antar lubang pada breadboard sangat penting sehingga kapan waktu untuk menggunakan kabel untuk menghubungkan antara satu lubang dengan lubang. Selain menggunakan EEPROM, data dapat disimpan menggunakan SD card. Kelebhan SD card dibandingkan dengan EEPROM terletak pada fasilitas untuk membaca data dalam bentuk file. File dalam format CSV (Comma-separated value) pun bisa dibaca dengan mudah (1). Untuk mengeluarkan hasil suara nya dapat menggunakan Speaker, Speaker adalah perangkat keras output yang berfungsi mengeluarkan hasil pemrosesan oleh CPU berupa audio/suara. Speaker juga bisa di sebut alat bantu untuk keluaran suara yang dihasilkan oleh perangkat musik seperti MP3 Player, DVD Player dan lain sebagainya (2). Untuk menguatkan suara yang dihasilkan nantinya akan di bantu dengan Amplifier Mini yaitu rangkaian komponen elektronika yang dipakai untuk menguatkan daya (atau tenaga secara umum). Dalam bidang audio, amplifier akan menguatkan signal suara berbentuk analog dari sumber suara yaitu memperkuat signal / gain arus dan tegangan listrik berbentuk sinyal AC dari inputnya menjadi arus listrik AC dan tegangan yang lebih besar, juga dayanya akan menjadi lebih besar di bagian outputnya (4). Dalam pengerjaaan nya penulis juga menggukan Software Arduino IDE. Arduino juga menggunakan software (IDE) Integrated Development Environment merupakan aplikasi yang mencakup editor, compiler, dan uploader Sketch yang digunakan untuk menulis program kedalam Arduino. Bahasa pada program yang digunakan untuk program yaitu bahasa C. (5). Berdasarkan latar belakang masalah diatas penulis merumuskan masalah yaitu merancang alat bel otomatis menggunakan Arduino Uno ATMega328p dengan modul RTC DS3231 (Real Time Clock) serta dapat mengeluarkan output suara yang berfungsi menyampaikan informasi untuk proses belajar mengajar

\section{Metode Penelitian}

Metode penelitian yang digunakan dalam penelitian ini adalah cara sistematis untuk tujuan mendapatkan jawaban yang akurat sesuai dengan pertanyaan pada objek penelitian serta mengetahui suatu rangkaian sistematis. Pada penelitian ini akan membahas tentang pembuatan dan perancangan Bel Otomatis di STIKOM Tunas Bangsa Berbasis Arduino dilengkapi dengan output suara. Perancangan sistem bel otomatis ini meliputi perangkat keras (Hardware) dan perangkat lunak (Software),

\subsection{Analisa Data}

Pada tahap analisa data peneliti menguraikan dan menjelaskan upaya pengolahan data penjadwalan yang akan diinput ke dalam program Arduino IDE. Dibawah ini adalah tabel penjadwalan proses belajar mengajar di STIKOM Tunas Bangsa dapat dilihat pada tabel 1 dibawah ini.

Tabel 1. Jadwal Proses Belajar mengajar di STIKOM Tunas Bangsa Pematangsiantar

\begin{tabular}{|c|c|l|}
\hline Sesi & \multicolumn{1}{|c|}{ Jam } & \multicolumn{1}{|c|}{ Keterangan } \\
\hline Pagi & $08.00-09.40$ WIB & Masuk Mata Kuliah 1 \\
\hline & $09.40-10.00$ WIB & Istirahat \\
\hline & $10.00-10.40$ WIB & Masuk Mata Kuliah 2 \\
\hline Siang & $14.00-15.40$ WIB & Masuk Mata Kuliah 1 \\
\hline & $14.50-16.10$ WIB & Istirahat \\
\hline & $16.10-17.50$ WIB & Masuk Mata Kuliah 2 \\
\hline Malam & $18.00-19.30$ WIB & Masuk Mata Kuliah 1 \\
\hline & $19.30-21.00$ WIB & Masuk Mata Kuliah 2 \\
\hline
\end{tabular}




\subsection{Alat Analisis Data}

Perancangan bel otomanis menggunakan modul RTC ( Real Time Clock), DFP Mini Player berbasis Arduino ATMega328p, maka dalam analisis data ini peneliti memilih menggunakan teknik analisis deskriptif yang presentasi nya dalam bentuk sebuah tabel termasuk perangkat keras (Hardware) dan perangkat lunak (Software) berikut ini :

\section{Perangkat Keras (Hardware)}

Dapat diamati komponen dalam pengerjaan bel otomatis berbasis Arduino Uno ATMega328p pada tabel 2 dibawah ini.

Tabel.2. Perangkat Keras

\begin{tabular}{|l|l|}
\hline No & Nama Perangkat Keras \\
\hline 1 & Adaptor 5V DC \\
\hline 2 & Arduino Uno \\
\hline 3 & RTS DS3231 \\
\hline 4 & Keypad LCD 16x2 Shield \\
\hline 5 & DFP Mini Player \\
\hline 6 & Speaker \\
\hline 7 & Memory Card \\
\hline 8 & BreadBoard \\
\hline 9 & Jumper Wire \\
\hline
\end{tabular}

\section{Perangkat Lunak (Software)}

Dalam pembuatan bel otomatis perangkat lunak sangat dibutuhkan untuk menjalankan sistem dengan program serta algoritma yang sesuai dengan yang dibutuhkan. Dapat dilihat dibawah ini pada tabel 3 adalah (Software) yang digunakan.

Tabel 3. Tabel Perangkat Lunak

\begin{tabular}{|l|l|}
\hline No & Nama Perangkat Lunak \\
\hline 1 & Software Fritzing \\
\hline 2 & Software Arduino IDE \\
\hline
\end{tabular}

\subsection{Instrumen Penelitian}

Dalam instrumen penelitian ini akan dijelaskan proses alur dari percobaan pembuatan bel otomatis. Berikut dibawah ini adalah alur percobaan pembuatan bel otomatis dapat dilihat pada gambar 1 berikut:

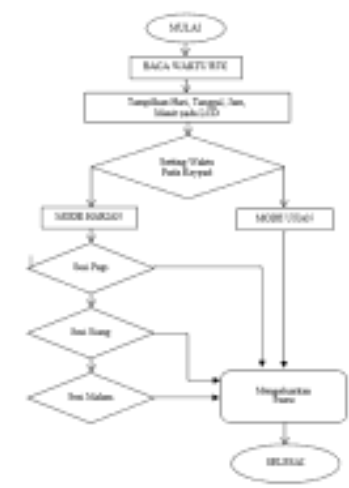

Gambar 1. Alur Proses Percobaan

Berikut ini adalah keterangan alur proses percobaan bel otomatis sampai selesai yaitu :

1. Pada saat Arduino aktifkan yang pertama akan dilakukan yaitu menginisialisasi pada RTC (Real Time Clock) untuk menampilkan waktu, hari dan tanggal pada $L C D$.

2. Jika mode yang digunakan adalah mode ujian maka akan dilakukan penyetingan waktu sesuai dengan jadwal ujian sesi pagi, sesi siang, sesi malam. 
3. Jika mode yang digunakan adalah mode regular (Harian) maka sistem akan bekerja secara otomatis sesuai jadwal yang telah ditanamkan ke dalam program Arduino melalui modul RTC (Real Time Clock).

4. Mode yang digunakan telah sesuai dengan jadwal yang telah disetting ataupun telah input dalam program maka akan mengeluarkan output berupa bentuk informasi pemberitahuan dalam proses belajar mengajar.

\subsection{Pemodelan Metode}

Pada pemodelan metode sistem akan di uraikan yang meliputi komponen-komponen yang digunakan dalam pembuatan bel otomatis dari mulai perangkat lunak, perangkat keras, serta argumen mengenai jenis-jenis komponen yang digunakan untuk mendukung kinerja bel otomatis.

1. Blok Diagram Bel Otomatis

Dapat dilihat blok diagram dari perancangan bel otomatis dibawah ini pada gambar 2 berikut ini:

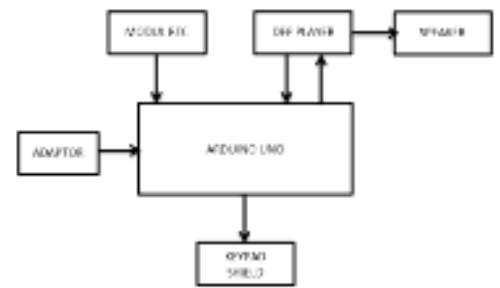

Gambar 2. Blok Diagram Bel Otomatis

Dibawah ini adalah penjelasan fungsi dari rangkaian pada gambar 2 sebagai berikut.

a. Blok Adaptor diatas berfungsi sebagai pemberi tegangan untuk sumber tegangan sebagai pengaktifan seluruh komponen.

b. Blok Keypad Shield 16x2 LCD berfungsi sebagai indikator untuk menampilkan waktu, hari, jam, tanggal, tahun dari RTC.

c. Blok RTC (Real Time Clock) berfungsi sebagai penyedia penyimpanan data seperti tanggal, hari, bulan, tahun yang dapat beroperasi dalam format waktu 12 jam ataupun 24 jam.

d. Blok DFP Player adalah komponen yang berfungsi untuk memainkan suara atau audio yang filenya telah disimpan di SD Card yang nantinya akan memainkan audio pemberi informasi proses belajar mengajar sesuai dengan waktu yang telah di input.

e. Speaker disini berfungsi sebagai pengeras suara outputan dari DFP player yang berupa audio.

f. Blok Arduino uno berfungsi sebagai pengolah data untuk menggerakkan komponen-komponen seperti $R T C$, DFP Player, Keypad Shield 16x2 LCD.

\subsection{Perancangan Perangkat Keras}

Perangkat keras (Arduino) adalah rangkaian input dan output sebagai penggerak semua sistem komponen yang terhubung pada Arduino dengan menggunakan catu daya adaptor $5 \mathrm{~V}$ DC yang masuk ke dalam melalui resistor untuk mengamankan komponen jika terjadi kerusakan karena lebihnya arus yang masuk.

Berikut dibawah ini rangkaian elektronik bel otomatis pada gambar 3 berikut:

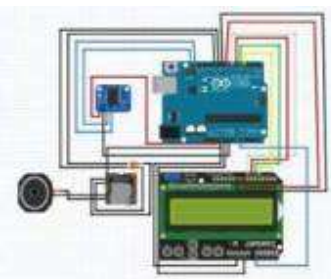

Gambar 3. Rangkaian Elektronik Bel Otomatis

Arduino ATMega328p adalah Board Mikrokontroler yang memiliki 14 pin digital yang 6 diantara nya adalah PWM output, arus DC tiap pin I/O $20 \mathrm{~mA}$, tegangan pengoperasian sebesar 5V, koneksi USB, memiliki Flash memory sebesar $32 \mathrm{~KB}$ yang cukup untuk menampung kode program yang lumayan banyak.

\subsection{Perancangan Perangkat Lunak}

JURNAL ILMIAH TEKNOLOGI INFORMASI DAN KOMUNIKASI (JTIK) VOL 12, No.2, September 2021, pp. 58 $-68$ 
Perancangan perangkat lunak adalah proses penginputan program yang sesuai dengan algoritma untuk merealisasikan metode alat. Pemrograman dibuat menggunakan Software Arduino IDE dimana software ini terdiri dari beberapa tools untuk menulis program, sebuah tools untuk memasukkan library, serta menghubungkan board yang akan digunakan. Didalam Kode program ada void setup yang merupakan inisialisasi yang dibutuhkan sebelum program di upload. Void Loop yang merupankan kode program perulangan yang akan digunakan yang merupankan kode program perulangan yang akan dijalankan selama modul terhubung dengan catu daya atau power supply. Berikut dibawah ini adalah contoh perancangan perangkat lunak program awal di dalam Arduino IDE dapat dilihat pada gambar 4 berikut:

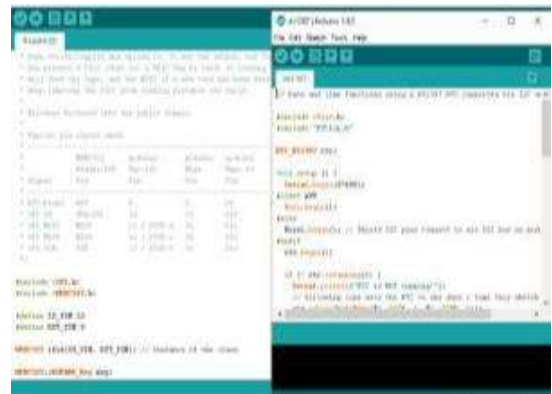

Gambar 4. Program Utama

\section{Hasil dan Pembahasan}

Alat yang dirancang peneliti akan diterapkan dan disimulasikan dalam bentuk prototype. Alat ini akan bekerja apabila waktu yang telah di input ke dalam Arduino Uno dengan menggunakan library RTC DS3231 sesuai dengan waktu yang sekarang maka, secara otomatis bel akan mengeluarkan suara melalui speaker yang mana suara tersebut dihasilkan dari SD Card berbentuk file yang berada di dalam modul DFP Player yang berbentuk sebagai informasi dan pemberitahuan. Pembuatan Prototype bel otomatis berbasis Arduino Uno, peneliti memerlukan pengumpulan data yang sesuai untuk kebutuhan yang diperlukan baik dari jurnal ataupun referensi dan buku yang dapat dipertanggung jawabkan kebenarannya agar tidak terjadi kendala yang tidak diinginkan dalam proses pembuatan alat bel otomatis. Selanjutnya alat yang dirancang peneliti akan diuraikan dalam beberapa tahapan.

Hasil dari perancangan bel otomatis dilakukan mulai dari input modul RTC agar dapat menginput jadwal waktu, kemudian memberikan hasil rekaman berbentuk file agar dapat memberikan sebuah intruksi atau pemberitahuan dan yang terakhir adalah menggabungkan semua inputan agar dapat diproses dalam Arduino Uno. Berikut ini adalah hasil akhir dari alat dapat dilihat pada gambar 5 dibawah ini.

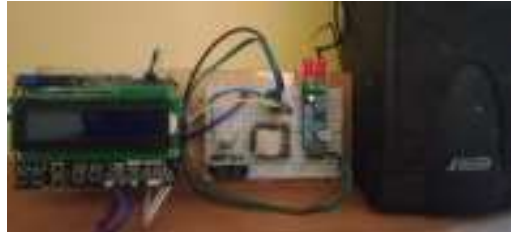

Gambar 5 Hasil Rangkaian Bel Otomatis

\subsection{Rancangan Arduino Uno ATMega328p}

Dalam hal ini nantinya akan dijelaskan bagaimana cara kerja sistem Arduino Uno ATMega328p untuk itu, terlebih dahulu penulis akan menjelaskan rancangan pembuatan alat Bel Otomatis berbasis Arduino Uno ATMega328p. Dalam perancangan dan pembuatan alat ini Microcontroller Arduino Uno ATMega328p akan dipadukan dengan beberapa modul seperti modul RTC, DFP Player, Ampli Player Mini dan berbagai komponen pendukung lainnya seperti SD Card, Keypad Shield 16x2, Adaptor, Kabel Jumper, Kabel USB, Speaker mini, Papan Board.

Berikut skema rangkaian bel otomatis yang telah dirakit menggunakan Fritzing.

Rangkaian RTC ke Aduino Uno ATMega328p

RANCANG BANGUN BEL OTOMATIS DI STIKOM TUNAS BANGSA BERBASIS ARDUINO DILENGKAPI DENGAN OUTPUT SUARA - Fachrul Hasby ${ }^{1}$ 


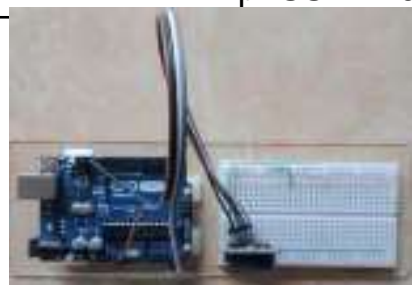

Gambar 6. Rangkaian RTC ke Arduino Uno

Tabel 4. Pin RTC Ke Arduino Uno

\begin{tabular}{|l|l|l|}
\hline No & Pin RTC & Pin Arduino \\
\hline 1 & GND & GND \\
\hline 2 & VCC & 3 V 3 \\
\hline 3 & SDC & A5 \\
\hline 4 & SDC & A4 \\
\hline
\end{tabular}

Dari skema rangkaian $R T C$ diatas telah dihubungkan dengan Arduino Uno ATMega 328p dengan pin GND pada $R T C$ masuk ke pin GND Arduino Uno, VCC pada RTC masuk ke $3 V 3$ Arduino Uno, pin SDA pada $R T C$ masuk ke pin $A 5$ dan pin $S C L$ masuk ke pin A4.

Rangkaian LCD Keypad Shield $16 \times 2$ ke Arduino Uno

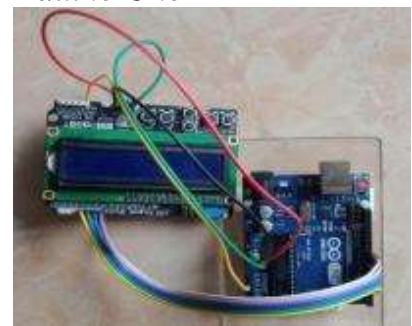

Gambar 7. Rangkaian LCD ke Arduino Uno

Tabel 5 Pin LCD Ke Arduino Uno

\begin{tabular}{|l|l|l|}
\hline No & Pin Arduino & Pin LCD \\
\hline 1 & $3 \mathrm{~V} 3$ & $3 \mathrm{~V} 3$ \\
\hline 2 & $5 \mathrm{~V}$ & $5 \mathrm{~V}$ \\
\hline 3 & GND & GND \\
\hline 4 & A0 & A0 \\
\hline 5 & $\sim 9$ & D9 \\
\hline 6 & 8 & D8 \\
\hline 7 & 7 & D7 \\
\hline 8 & $\sim 6$ & D6 \\
\hline 9 & $\sim 5$ & D5 \\
\hline 4 & 4 & D4 \\
\hline
\end{tabular}

Dari rangkaian skema dan tabel diatas dapat dilihat tegangan $3 \mathrm{~V} 3$ dan $5 \mathrm{~V}$ pada Arduino Uno dihubungkan ke $3 \mathrm{~V} 3$ dan $5 \mathrm{~V}$ pada $L C D$ yang berfungsi untuk daya nya. Pin $G N D$ (pin negatif) pada Arduino dihubungkan ke GND pada $L C D$, selanjutnya pin analog pada Arduino Uno (A0) dihubungkan ke pin A0 yang ada pada $L C D$ yang berfungsi sebagai pengatur waktu. Terdapat pin analog input dan output serta PWM dalam Arduino yaitu $\sim 9,8,7, \sim 6, \sim 5,4$ pin-pin ini akan dibubungkan pada $L C D$ sesuai dengan nomor pinnya yaitu D9, D8, D7, D6, D5, D4 yang berfungsi untuk membaca sinyal input dan output dengan kondisi HIGH atau pun $L O W$.

Rangkaian DFP Player, Am `lifier dan Speaker ke Arduino Uno 


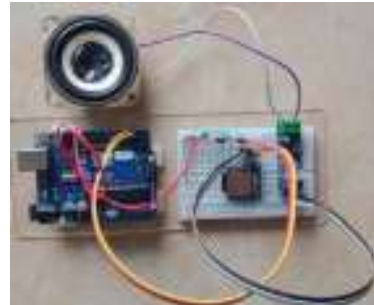

Gambar 8. Skema DFP Player, Amplifier dan Speaker ke Arduino

Tabel 6 Pin DFP player dan Amplifier ke Arduino

\begin{tabular}{|c|c|c|c|c|}
\hline No. & Arduino Uno & DFP Player & Amplifier & Speaker \\
\hline 1. & $5 \mathrm{~V}$ & VCC & V+ & \\
\hline 2. & 2 & TX & & \\
\hline 3. & $\sim 3$ & RX & & \\
\hline 4. & & DAC_R & -INPUT & \\
\hline 5. & & DAC_1 & +INPUT & \\
\hline 6. & GND & GND & GND & SP- \\
\hline 7. & & & SPOUT+ & SP- \\
\hline
\end{tabular}

Dapat dilihat pada skema rangkain Arduino Uno ke DFP Player, Amplifier dan speaker diatas pin $5 \mathrm{~V}$ dihubungkan ke VCC pada DFP Player, dan VCC pada DFP Player dihubungkan ke V+ pada amplifier, Pin analog 2 dihubungkan ke TX pada DFP Player, Pin $P W M \sim 3$ dihubungkan ke $R X$ pada DFP Player, DAC_R pada DFP player dihubungkan ke -INPUT pada Amplifier agar suara yang dihasilkan bisa jernih dan juga DAC_l dihubungkan ke +INPUT di amplifier, lalu GND pada Arduino Uno di hubungkan ke GND yang ada pada DFP Player, Amplifier dan Speaker, yang terakhir SPOUT+ pada Amplifier dihubungkan ke SP- pada Speaker.

2. Rangkaian Keseluruhan Bel Otomatis

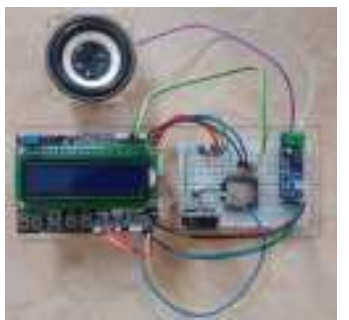

Gambar 9. Skema Rangkaian Keseluruhan Bel Otomatis

Dari skema rangkaian yang penulis buat, dapat dilihat satu persatu dari mulai gambar 6 skema rangkaian penghubungan antar pin yang akan dipakai pada setiap modul untuk dihubungkan ke pin yang ada di dalam Arduino Uno. Berikut setelah menghubungkan semua pin yang ada pada modul ke Arduino Uno proses selajutnya adalah menginput Code program yang telah dirancang menggunakan bahasa $C$ dengan Software Arduino IDE. Guna dari kode tersebut yaitu untuk memberikan sebuah perintah ke setiap modul agar bel otomatis yang telah dirancang dapat berfungsi seperti yang diharapkan.

\subsection{Pemrosesan ( Proses ) Sistem}

Data yang berasal dari Real Time Clock dan DFP Player Mini kemudian akan diproses oleh Microcontroller Arduino Uno. Setelah data hasil dari pemrosesan oleh Arduino Uno telah dilakukan maka Arduino Uno akan memberikan sebuah perintah kepada DFP Player untuk mengeluarkan suara melalui speaker sesuai dengan waktu yang telah ditanamkan dalam program di dalam RTC ( Real Rime Clock).

Dalam Serial Monitor, dapat dilihat proses dari bel otomatis sedang berjalan dengan waktu yang telah di tentukan di dalam modul RTC. Dapat dilihat pada gambar 10 dibawah ini. DILENGKAPI DENGAN OUTPUT SUARA - Fachrul Hasby ${ }^{1}$ 


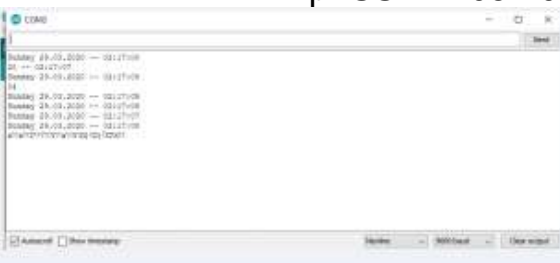

Gambar 10. Serial Monitor

\subsection{Keluaran ( Output ) Sistem}

Dalam pengerjaan bel otomatis penulis menambahkan hasil keluaran (Output) guna membantu dan melengkapi kinerja sistem agar bekerja optimal dan tepat waktu sesuai yang telah dijadwalkan. Penulis menggunakan output berupa suara perintah atau penyampaian informasi yang berasal dari modul DFP Player berupa file MP3 lalu di keluarkan oleh Speaker dan ditampilkan oleh $L C D$. Berikut dibawah ini adalah tampilan hasil keluaran output dari bel otomatis :

1. Mode Reguler

Hasil output pada mode regular atau mode harian akan ditampilkan pada LCD Keypad Shield 16x2 dimana pada hasil keluaran dalam mode regular ini meliputi beberapa sesi penjadwalan matakuliah di STIKOM Tunas Bangsa yaitu, sesi pagi, sesi siang, dan sesi malam. Berikut dibawah ini adalah hasil output nya masingmasing.

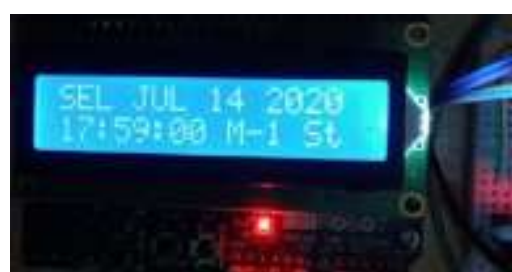

Gambar 11. Output mode harian

Gambar diatas adalah tampilan waktu di dalam $L C D$ untuk penjadwalan di mode harian pada bel otomatis.

\section{Mode Ujian}

Hasil output dalam mode ujian akan ditampilkan di dalam $L C D$ berbentu alarm yang mempunyai 4 kondisi yang dimulai dengan ujian 1 start, ujian 1 end, ujian 2 start, dan ujian 2 end. Dapat dilihat pada gambar dibawah ini.

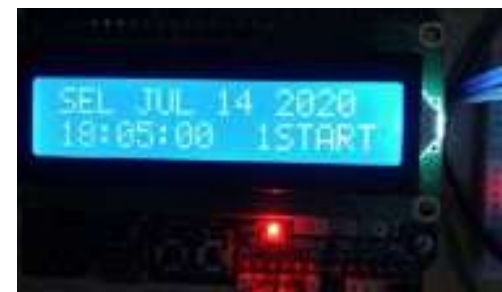

Gambar 12. Output Mode Ujian 1 Start

Gambar diatas adalah tampilan LCD Keypad Shield hasil output dari mode ujian 1 start.

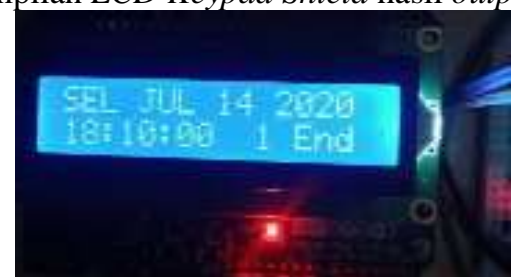

Gambar 13. Output Mode Ujian 1 End 
Gambar diatas adalah tampilan LCD Keypad Shield hasil output dari mode ujian 1 end.

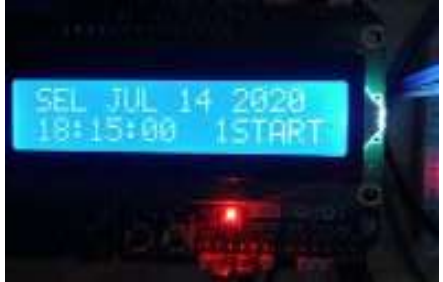

Gambar 14. Output Mode Ujian 2 Start

Gambar diatas adalah tampilan LCD Keypad Shield 16x2 hasil output dari mode ujian 2 start.

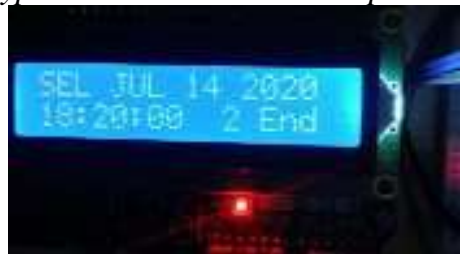

Gambar 15. Output Mode Ujian 2 End

Gambar diatas adalah tampilan LCD Keypad Shield hasil output dari mode ujian 2 end. Ada pun panduan langkah-langkah dalam penyetingan pada mode ujian dalam keypad shield yaitu :

a. Tekan tombol sellect 1 kali untuk mengganti tampilan ke mode alarm, lalu lekan tombol sellect selama 3 detik untuk menyettingnya dan merubah $O F F$ menjadi $O N$

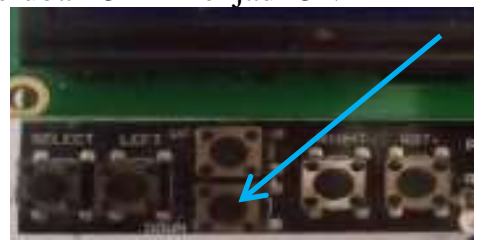

Gambar 16. Tombol Sellect

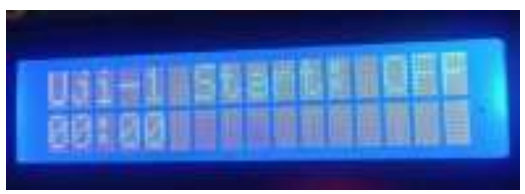

Gambar 17. Tampilan Alarm

b. Lalu tekan tombol RIGHT untuk menggeser kursor ke settingan waktu, setelah itu tekan tombol UP atau DOWN untuk men-setting waktu sesuai yang diinginkan.

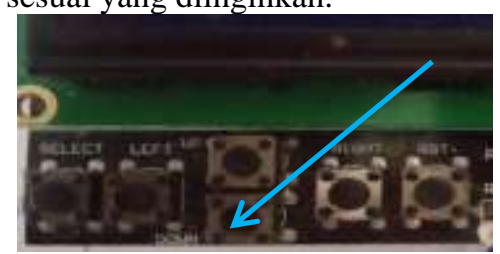

Gambar 18. Tombol Sellect

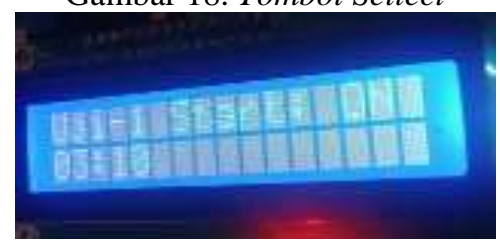

Gambar 19. Tampilan Alarm Setelah Disetting

RANCANG BANGUN BEL OTOMATIS DI STIKOM TUNAS BANGSA BERBASIS ARDUINO DILENGKAPI DENGAN OUTPUT SUARA - Fachrul Hasby ${ }^{1}$ 
c. Jika sudah selesai men-setting waktu yang diıngin kan maka tekan kembali tombol SELLECT nya dan begitu juga untuk men-setting alarm-alarm ujian selanjutnya.

\section{KESIMPULAN}

Setelah melakukan perakitan pada bel otomatis yang berbentuk Prototype dan telah melakukan pengujian pada alat bel otomatis maka, telah diambil beberapa kesimpulan dari keseluruhannya yaitu :

1. Alat bel otomatis yang telah dirakit penulis dapat bekerja secara otomatis dengan baik dan tepat waktu.

2. Modul DFP Player dapat mengeluarkan suara melalui file MP3 dengan output suara dalam bentuk informasi dengan jelas dan teratur.

3. Amplifier dan Speaker bekerja dengan baik dalam mengeluarkan suara yang kuat dan jelas.

4. Microcontroller Arduino Uno ATMega328p yang dikombinasikan dengan RTC dan LCD dapat bekerja dengan baik sehingga perancangan bel otomatis bekerja sesuai dengan yang diharapkan.

Dalam Perancangan bel motomatis penulis akan mencantumkan beberapa saran agar bel otomatis bekerja dengan lebih baik lagi dalam pengembangan selanjutnya, yaitu diantaranya.

1. Untuk penyimpanan waktu dalam jangka panjang lebih bagus dan lebih maksimal yaitu dengan memakai Eeprom karena jika pada saat mati lampu pada mode ujian maka waktu yang telah di setting tidak hilang atau terkena riset.

2. Microcontroller Arduino Uno lebih bagus memakai kapasitas memory yang besar agar cukup untuk menampung dan mengkombinasikan dengan modul-modul yang lebih banyak.

\section{Daftar Pustaka :}

[1] Abdul Kadir., (2018). ARDUINO MEGA Panduan Untuk Mempelajari Pembuatan Berbagai Proyek Elektronika.

[2] Alhamidi, A., \& Asmara, R. (2017). Rancang Bangun Timbangan Badan Output Suara Berbasis Arduino Uno R3. Jurnal Sains Dan Informatika, 3(2), 142. https://doi.org/10.22216/jsi.v3i2.2910

[3] Cholish, C., Rimbawati, R., \& Hutasuhut, A. A. (2017). Analisa Perbandingan Switch Mode Power Supply (SMPS) dan Transformator Linear Pada Audio Amplifier. CIRCUIT: Jurnal Ilmiah Pendidikan Teknik Elektro, 1(2), 90-102. https://doi.org/10.22373/crc.v1i2.2079

[4] Dendy Kurniawan., (2018). Rancang Bangun Alat Musik Piano, Harpa, Marching Bell Digital Berbasis Arduino Menggunakan Cahaya Laser dan LDR (Studi Kasus : SMP NU 07 Brangsong),. Vol 11, No.1

[5] Feriska, A., \& Triyanto, D. (2017). Rancangan Bangunan Penjemur Dan Pengering Pakaian Otomatis Berbasis Mikrokontroler. Jurnal Coding Sistem Komputer Untan, 5(2), 67-76.

[6] Linarta, A., \& Nurhadi, N. (2018). Aplikasi Bel Sekolah Otomatis Berbasis Arduino Dilengkapi Dengan Output Suara. I N F O R M a T I K A, 10(2), 1. https://doi.org/10.36723/juri.v10i2.108

[7] Marpaung, N. (2017). Perancangan Prototype Jemuran Pintar Berbasis Ardunio Uno R3 Menggunakan Sensor LDR Dan Sensor Air. Riau Journal Of Computer Science, 3(2), 71-80.

[8] Qory Hidayati, A. N. A. (2018). Rancang bangun bel otomatis berbasis rtc ds3231 menggunakan arduino uno r3 sebagai tanda pergantian jadwal. 6(1), 1-8.

[9] Sarmidil, A. N. (2019). Jurnal manajemen dan teknik informatika. Rancang Bangun Sistem Informasi Pengolahan Bank Sampah Puspasari Kecamatan Purbaratu Kota Tasikmalaya, 02(01), 181-190.

[10] Wardani, K. (2018). Rancang Bangun Modul Pembelajaran Komunikasi Data Serial untuk Mata Kuliah Komunikasi Data Program Studi Teknik Telekomunikasi. 2(November 2018).

[11] Yasin, M., \& Irfana, M. S. (2017). Bel Otomatis Virtual Dual Channel Berbasis Android. Systemic: Information System and Informatics Journal, 3(1), 33-40. https://doi.org/10.29080/systemic.v3i1.193 